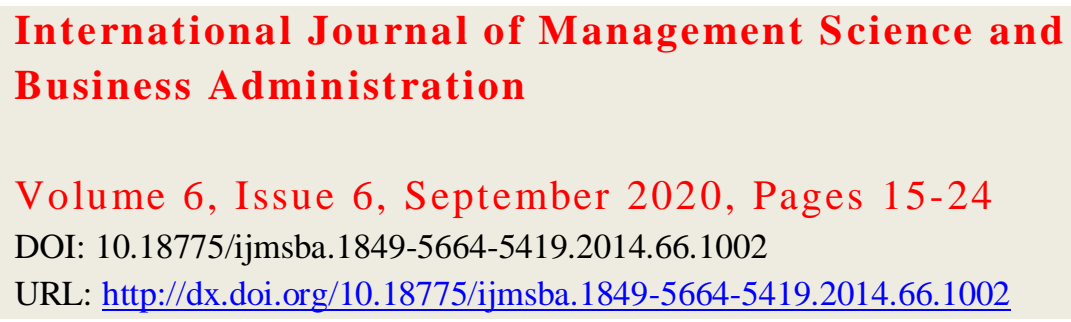

\title{
Influence of Covid-19 Crisis on Human Resource Management and Companies' Response: The Expert Study
}

\author{
Iza Gigauri \\ Associate Professor, School of Business, Computing and Social Sciences, \\ St. Andrews Georgian University, Tbilisi, Georgia
}

\begin{abstract}
Dramatic changes caused by the new coronavirus COVID-19 have unprecedented implications on companies around the globe and influenced human resource management profoundly. HRM took leadership to navigate in the vague present and unforeseeable future by managing people to cope with stress and to continue working remotely so that business goes on with its operations. However, HRM had to deal with the dismissals and reduction of the staff caused by the pandemic lockdown. The presented paper is based on the qualitative expert interview research method. It discusses the challenges HRM has been facing in Georgia, ascertains the implications the crisis has on human resources, finds out the solutions companies applied, and makes suggestions for tackling the crisis from the point of view of HRM. The expert interview findings indicate that companies, together with the HR managers, should develop crisis management plans, elaborate new policies for remote as well as hybrid working systems as a response to the current and future crises.
\end{abstract}

Keywords: Adaptability, Flexibility, Resilience, HRM, Employees, Remote working, Georgia, Work-life-balance, Digitalisation

\section{Introduction}

The economic effect of the global pandemic (Covid-19) includes acceleration of the digitalisation processes. Companies now need to immediately use digital platforms to enable access to jobs for their employees. Human Resource Management has an essential role to play in helping organisation to navigate in the situation of dramatic changes caused by the pandemic lockdown.

The research is induced by the situation in which business process continuity has been affected by the regulations aiming to prevent the spread of Covid-19, causing dismissals or reduction the staff.

The aim of this research is to estimate the level and magnitude of the challenge companies have been facing in terms of HRM, and to assume the consequences, what changes are expecting to be initiated.

The primary data for this research was gathered by semi-structured face-to-face video interviews. The theoretical framework and research questions were used to structure the data collection questions and to determine the analytical direction of the study.

The following research questions were determined for this study.

RQ1: Why and how did the Covid-19 affected companies and employees in general, and particularly in Georgia?

RQ2: Why and how did the pandemic conditions influence the HRM practice in the Georgian companies?

RQ3: How did HRM respond to the crisis in Georgia and whether HRM strategy has been worked out for the postpandemic period?

The research results present remarkable insights for HR managers and organisations. HR managers need to know how to improve the wellbeing of employees during virtual work in crisis times taking into consideration personal stress. Besides, 
internal corporate communication, company brand image should be in compliance with the organisation's approach to the workforce during turbulent times. Overall, the contribution of the manuscript to scholarship is its suggestion that main challenges triggered by the pandemic lockdown are the recession when revenues have been decreased enforcing companies to reduce or dismiss the staff. The research results recommend HR managers to acknowledge their dominant role in the heart of the changing processes of digitalisation towards remote working models, and of developing new HR policies. Resilience, flexibility, and adaptability are crucial overcoming strategies.

The rest of this paper is organised in the following way. First, a review of the literature on the Covid-19 pandemic crisis is presented. Next, the empirical data collection method as well as analytical framework is conceptualized. Then, primary research results are discussed followed by conclusions. Finally, future research topics are considered.

\section{Literature Review}

\subsection{The Role of HRM in the Adaptation of the Workforce}

Recently, the Covid-19 pandemic has created demanding conditions for human resource managers. In the context of dramatic changes around the world due to the pandemic, organisations need to respond and adapt to the alterations and accordingly manage the workforce (Carnevale \& Hatak, 2020). Sheppard (2020) argues that companies need to prepare for further changes and turbulence times. They should adopt technologies that are platform-based and develop novel business models (Sheppard, 2020). HRM has a significant role in helping employees to overcome the difficulties brought by the unexpected changes in the workplace as well as in the society (Carnevale \& Hatak, 2020). Besides, the digital and collaborative skills of the workforce are required to move to the virtual work (Sheppard, 2020).

As remote working from home intensifies, HRM has to cope with the stress of their employees associated with the removal boundaries between work and family (Giurge \& Bohns, 2020).

Moreover, the increasing unemployment due to the recession imposes more pressure on the people. The International Labour Organisation (ILO) (2020) estimates that 195 million full-time workers will lose their jobs worldwide this year (ILO, 2020). Therefore, employees need to learn new skills that increase their employability in the digital space (Sheppard, 2020). In this regard, HR managers should elaborate strategies enabling employees to use advanced technologies as well as update their digital skills (Parry \& Battista, 2019). In addition, lifelong learning and developing talents is still important, but training sessions take place online (Narayandas, Hebbar, \& Liangliang, 2020). Interestingly, the leaders of the surveyed Chinese companies did not conserve resources but rather invested intensively to increase their competitiveness (Narayandas, Hebbar, \& Liangliang, 2020).

Consequently, HR professionals have a facilitating and supporting role in this transformation, but they also take responsibility to retain the employees by upgrading their skills and abilities (Parry \& Battista, 2019). Not only reskilling or upskilling of the workforce is essential, but resilience should be equally prioritised within a company's strategy (Kirby, 2020) The extensive survey of 869 teams and 11,011 workers in European countries demonstrates that remote working is not valuable for all employees, and team performance even lowers when team members work remotely, specifically when they work more than 8 hours per week (Van der Lippe \& Lippényi, 2019). Yet individual performance factors such as work characteristic, satisfaction, and commitment should also be taken into account (Van der Lippe \& Lippényi, 2019) when HRM coordinates flexible or hybrid work. Besides, employees' wellbeing and health have implications on their outcomes. Consequently, work and private life mixture during remote working from home can be the core challenge HRM is facing (Peasley, Hochstein, Britton, Srivastava, \& Stewart, 2020).

The research conducted at Microsoft explored that the major difficulties during the pandemic were business continuity, employee wellbeing, and customer orientation (Singer-Velush, Sherman, \& Anderson, 2020). Managers are striving to reduce possible harmful effects of working from home help the workers in setting priorities (Singer-Velush, Sherman, \& Anderson, 2020). On the other hand, less socialisation during the pandemic have implications on the employees' mental health. Therefore, HR practitioners need to respond also this challenge by arranging virtual meetings or online relationships to maintain the motivation and productivity of employees (Singer-Velush, Sherman, \& Anderson, 2020). Furthermore, remote working makes it difficult to control and monitor employees' activities. The potential solution managers have found is using online dashboards, and digital data for assessing workload and performance (Narayandas, Hebbar, \& Liangliang, 2020). 
In order to build a culture of flexibility, an organisation should enable creativity and agility without a formal policy guide, and taking into account the individual needs of each employee (Donovan, 2019). According to Donovan (2019), flexibility means a happier and productive workforce.

Thus, HRM should take the lead in helping organisations to navigate through uncertainties, taking into consideration the needs of developing skills and of maintaining mental wellbeing of employees. Companies planning for the future need to adjust their focus on business continuity as well as supporting organisational health.

\subsection{Effects of the Covid-19 Crisis on Georgian Companies}

According to the survey of Georgian Chamber of Commerce and Industry, the main challenges companies in Georgia have reported are reduced sales (for 53\% of them), the exchange rate (13\%), and transportation problems (13\%) (GCCI, 2020). Decreased demand and disruption in the supply chain among all sectors resulted in decreased revenue; especially the accommodation and food service companies are negatively affected (PwC Georgia, 2020). 63\% of surveyed companies stated that their revenues dropped by more than $50 \%$ in comparison with the last year (PwC Georgia, 2020). As a result, more than $50 \%$ of companies in Georgia have reduced staff, and $40 \%$ of companies in the tourism sector dismissed all their employees (PwC Georgia, 2020).

It should be noted that the agriculture sector appears to be less vulnerable also in Georgia (PwC Georgia, 2020). However, many companies in other sectors suspended business operations or even shut down production due to the pandemic, but the most medium and large companies switched to teleworking (PwC Georgia, 2020).

According to the survey of the Georgian Chamber of Commerce and Industry, $66 \%$ of Georgian companies suffered financial loss, and business turnover in $76 \%$ of companies for the last six months decreased (GCCI, 2020). However, $53 \%$ of the surveyed companies intend to maintain their employees for the next six months, but $43 \%$ of the employers have reduced the salaries (GCCI, 2020).

Businesses see the solution in financial aid and long-term/ soft loan, as well as in reduction or temporary cancellation of taxes; only $3 \%$ of them stated that they do not need any assistance (GCCI, 2020).

In this light, how does HRM in Georgia affected by the crisis situation, and how HR managers should overcome the challenges they are facing under the circumstances of uncertainty. In this vein, the present research includes the recommendations for companies coping the pandemic crisis from the viewpoint of the HR experts.

\section{Data Collection Procedures}

For this research, exploratory qualitative approach was used, as its aim was to study the impact of the Covid-19 pandemic crisis on the organisations and in particular on HRM. The semi-structured open interview was considered to be appropriate as it provides the room to explore the thoughts and reflections of an expert.

For the expert interview, the following procedures were implemented (Figure 1): After selecting a research topic, preparation and planning phase begun, which followed by conducting sessions of video interviews. Then transcripts of the recorded interviews were made. Afterwards the data were analysed, discussed, and interpreted, and finally conclusions and recommendations based of the results were made.

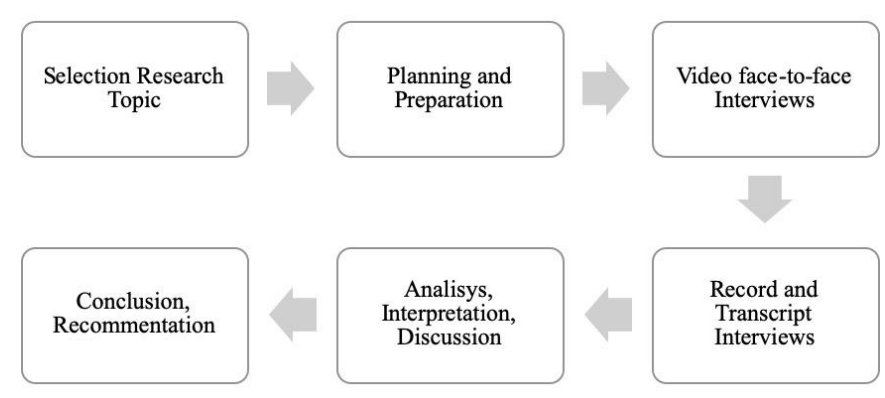

Figure 1: Research Procedure 


\subsection{Data Collection Instrument}

Based on interview guideline, the primary data were collected through Expert interviews conducted in April and May 2020. The experts were selected on the ground of purposive sampling approach. The characteristics of respondents were the main factors to choose participants.

According to Corbin and Strauss (2008), the methodology of the research is determined by the research questions, and qualitative research approach help researchers to discover instead of testing variables (Corbin \& Strauss, 2008).

\subsection{Expert Interview}

The Expert Interview Method was applied to collect data for this study. The expert interview as an exploratory tool is considered as a widely used in empirical studies for the data gathering (Bogner, Littig, \& Menz, Interviewing Experts, 2009).

An expert possesses technical, interpretative, process knowledge in a specific competences field (Bogner, Littig, \& Menz, Introduction: Expert interviews - An introduction to a new methodological debate, 2009), and has experience (Mergel, Edelmann, \& Haug, 2019). An expert has access to information and can solve problems in their field of expertise (Meuser \& Nagel, 2002). Competent experts have relevant education and skills, position, work experience in the area of the research topic, as well as they can be publicly recognised (Libakova \& Sertakova, 2015).

Based on the abovementioned research regarding expert definition, the following criteria were developed to invite experts for the interview (Figure 2): (1) having theoretical knowledge as well as expertise gained in praxis in the area of human resource management, (2) having experience in working with organisations regarding human resource management issues, (3) be involved in research at the university level, or in consulting, and training activities and hence, have direct connections with HR managers in Georgian companies.

Thus, the experts invited to participate in this research are close to the various organisations in Georgia because of their work, and have frequent and immediate relations with HR managers in the course of their day-to-day activities. Consequently, they regard the present situation and effects of the pandemic.

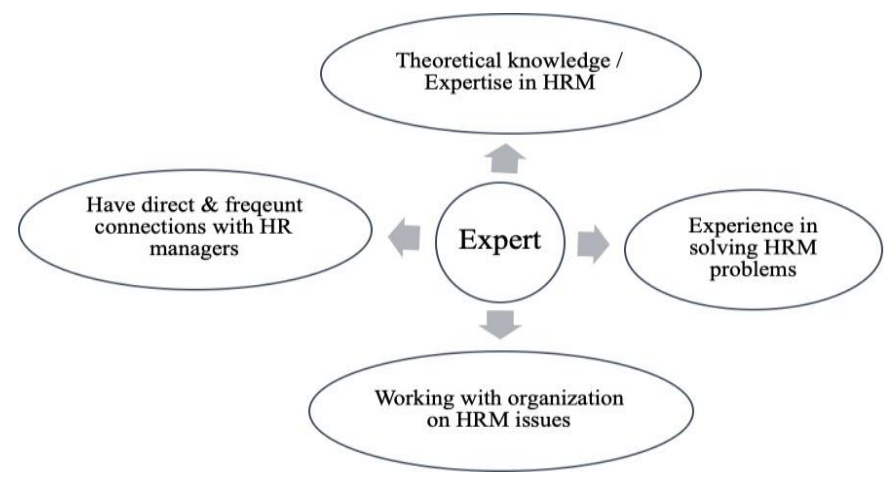

Figure 2: Experts Selection Criteria

Data collection from an expert interview involves the video recording, transcript in Georgian and translation into English. The face-to-face expert interviews were conducted in April and May this year through online video platform Zoom. Every interview was prescheduled, carried out in the Georgian language, and transcripts were later translated into English. The depth interview with an individual expert took between 23 and 46 minutes. The experts were asked to allow videorecording in Zoom in order to transcript it later. They were ensured that their personal data will be protected.

The semi-structured interview followed similar guideline that enabled to compare data, and to keep the interview within the topic boundaries. At the end of the interview, the last question was about their additional comments or viewpoints they thought it could be important to this study. 
The questions were based on the current literature, and relied on the expert answers to pose additional questions. The questions were open-ended and comprehensive answers were expected. Overall, the interview outline consisted of 9 questions covering the 6 main themes (Table 1).

Table 1: Main Interview Themes

\begin{tabular}{|l|l|}
\hline Part & Theme \\
\hline I & General question about the expert experience and precise field of expertise \\
\hline II & Questions about Covid-19 effect on organisations and challenges HRM have been facing \\
\hline III & Questions about changes caused by the crisis (e.g. Work-life balance, Digital transformation) \\
\hline IV & Questions about the company response to the pandemic crisis from HRM perspective \\
\hline V & $\begin{array}{l}\text { Expert opinions regarding the future of HRM, and their recommendations to HR } \\
\text { managers }\end{array}$ \\
\hline VI & Additional thoughts/ views if applicable \\
\hline
\end{tabular}

In the framework of this paper, questions in part 2 and 5 are analysed. The experts were asked what they consider as the most challenging for Georgian companies during the pandemic, how they are affected, how HRM will be changed in the post-pandemic period, and if any opportunities regarding digitalisation and employee wellbeing have been revealed.

\subsection{Sampling}

The number of potential interviewees is determined by the research question, as well as by accessibility to and availability of experts (Baker \& Edwards, 2012). It should be noted, that the number of experts may be limited in the particular area, and hence maximum ten interviews should be conducted (Baker \& Edwards, 2012). Ten interviews with experts is considered to be sufficient to analyse appropriately (Glaser \& Strauss, 1967). However, data collection should stop when saturation is reached (Glaser \& Strauss, 1967). Purposive sampling is a broadly used method in nonprobability sampling the size of which depends on the idea of saturation meaning that "no new information or themes are observed in the data" (Guest, Bunce, \& Johnson, 2006). Based on the results of their research, saturation takes place within the first twelve interviews, however fundamental themes occur within the first six interviews (Guest, Bunce, \& Johnson, 2006). Cooper and Schindler (2014) confirmed that sampling in expert interviews should be kept as long as it brings new insight, and terminate when there is no new knowledge obtained (Cooper \& Schindler, 2014).

Totally, 33 experts were invited to the face-to-face video interview, from which 10 were actually interviewed. Experts were recruited through the professional contacts of the researcher. Initially, we contacted them via Email explaining the purpose of the research and sending them preliminary interview questions.

The respondents are experts of the domain of human resource management, and the data they provided is true reflection of current state in this area. Their experience and insight allow gathering primary data from various background and experience in order to study the impact of the crisis.

The experts stem from various organisations ranging from consulting companies to training centres to universities. Namely, Training and Consulting: $n=6$, University: $n=3$, only Consulting: $n=1$. Seven of the interviewees were female, and three - male. Their working experience in HRM consulting, training, and research field ranges between 9 and 25 years (see Figure 3).

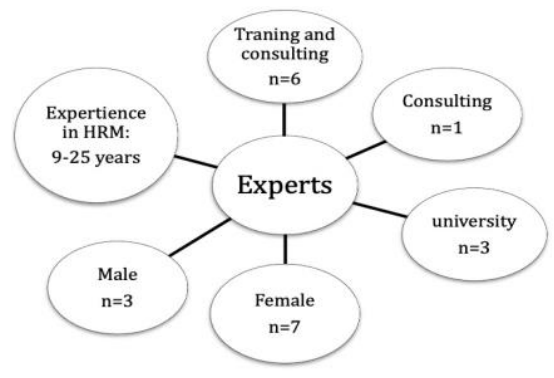

Figure 3: Background of the experts 


\subsection{Data Analysis}

At the stage of the analysis, the collected data through the expert interview were interpreted and analysed with the approach of qualitative content analysis.

The systematic analysis includes concepts, themes, and categories derived from the data, which are discussed (Silverman, 2000). The thematic parts and passages with similar elements have been noticed (Bogner, Litting \& Menz, 2009). Additionally, the data were grouped and labelled by category; relevant themes to the research questions were determined to make connections (Flick, 2014).

Thus, themes, issues, categories were identified, patterns were discovered in the content, and were labelled appropriately. Then, data were sorted according to similar themes and subthemes as well as conflicting points of view. Thematically similar passages from different expert interviews were put together as described by Bogner, Litting and Menz (2009) to further conceptualize and reveal the commonly shared expert opinions.

\section{Research Findings and Discussion}

\subsection{Disruptions in HRM Caused by Pandemic}

Interviewed experts confirm that the unexpected emerged situation provoked apparently a shocking reaction, and exposed that companies were inexperienced in crisis management. It took Georgian companies at least 2 weeks to switch to online mode. First of all, service companies were extremely affected, as they could not meet customers face-to-face, so those activities were totally cancelled. Even when service companies managed to transform their offers such as training, consulting, or coaching sessions to online working systems, not all of their clients were ready to accept the digital services, and preferred to wait until the crisis is over. The interviewees clearly state the problem of flexibility among Georgian companies.

"Some companies cannot be so flexible; especially large companies find it difficult to transfer all processes online quickly" (R4, my translation).

The main focus in Georgian economy has been on tourism and entertainment industries in terms of revenue, as this industry enables to make relatively more profit with relatively less investment. In consequence of the pandemic lockdown, Georgian companies in tourism, hospitality, food, and entertainment business have encountered serious problems. Companies are now attempting to focus merely on survival. "It is no longer a question of profit, but to survive in the market" (R6, my translation).

In the field of tourism, it has become clear that many companies have closed or are on the verge of closing. For that reason, many people have become unemployed, and overall, the purchasing power of the population is falling.

In general, the respondents mentioned three types of cases they observed in terms of companies' attitudes towards employees: (1) Some companies have been closed and hence dismissed all employees. (2) Many companies have retained employees by sending to unpaid leaves. (3) There are companies that retained employees giving them salaries. However, some companies managed only to retain the senior staff with salaries (Figure 4).

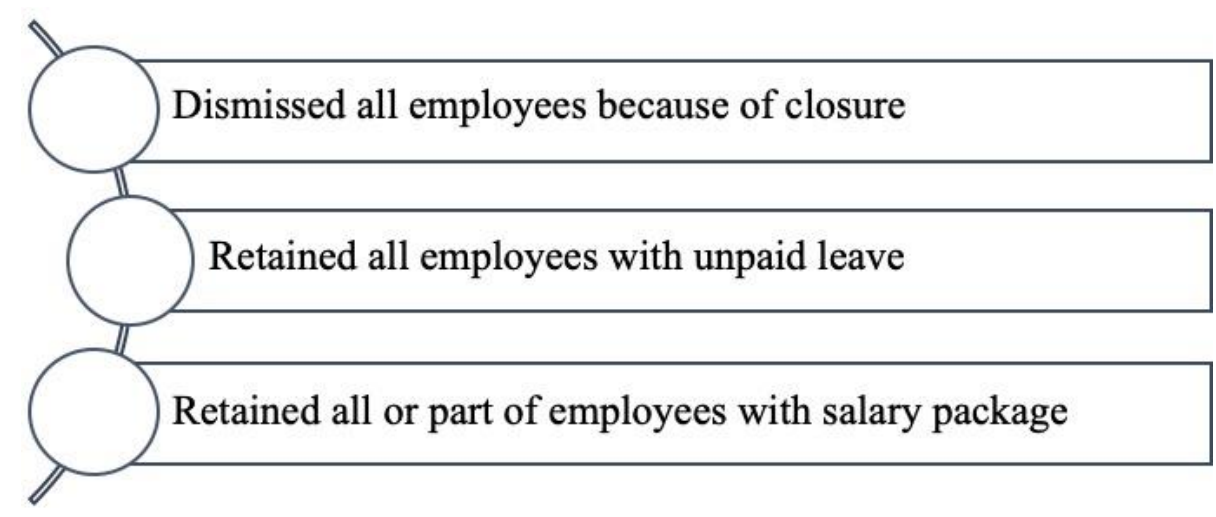

Figure 4: Type of Georgian companies according to their approach towards employees 
Moreover, the recruitment of new staff has been reduced as well, companies do not intend to hire new workers at the moment. "Companies hire only temporarily with contract to carry out ongoing projects" (R5, my translation).

In addition, systemic deficiencies and unpreparedness have been reported in many cases in terms of business continuity.

\subsection{Major Obstacles for HRM Concerning the Workforce}

The experts reported in the interviews that the crisis significantly has reflected the corporate brand and organisational culture. The pandemic crisis showed how corporate brand actually corresponds to the communicated brand, and it have had either a positive or drastically negative impact on the relationships between management and employees. The company image can face the challenge caused by the organisation's attitude towards employees during the pandemic period. The experts see significant failures in internal corporate communications as well.

During the pandemic period, some companies experience high turnover because the management demonstrated values different those from employees. Obviously, not all companies have taken responsibility for their workers. Dismissals, cuts in salaries, granting unpaid leaves have led to the changed attitudes towards the organisation.

According to the expert R3:

"Those who stay in such a situation because they did not have any other job opportunities at the moment, are demotivated, which definitely affects the company in the short- and medium-term; this will influence the quality of service, the products as well as on the clients" (my translation).

Even when all employees have not been fired, the psychological stress, fear, and insecurity of the rest workforce are so high that the degree of loyalty in organisations decreases. Moreover, when the employees leave companies, the knowledge such as experience, skills, internal communications, might be lost, and organisational culture suffers eventually.

Although many companies have overcome many challenges during the lockdown, the most of them have not yet had any prevention mechanism in place.

Interviewees were concerned about the challenges HR managers have faced in the course of the Covid-19 crisis. HR professionals needed to try to prevent dismissals and retain employees.

Regarding the impact on employees' development, Georgian companies facing the recession due to the pandemic, will not be able or willing to invest in human potential development. As the management is trying to save costs, yet without trainings, consulting, and coaching employees could not be developed, which causes problems to HRM function in accomplishing their goals. Besides, companies are trying to spend less on employee development, which will have impact on employee motivation, retention, well-being, as well as on company's effectiveness, further advancement, and its ultimate success on the market.

In the opinion of experts, the main challenge was that companies had to quickly switch to different behaviours i.e. working from the office to remote working systems using online tools. However, not everyone was able or ready to make such big changes, but they rather suspended the operations until the virus passes, as they believe that everything will go back to the usual circle again.

Besides, HRM function does not possess the necessary knowledge in technologies, and hence was not able to take a leadership in this process on their own. They faced also the administration challenges such as management of dismissal, regulations, and so on. For example, many HR specialists were not willing to conduct training sessions through the Internet, and postponed those activities until it is possible face-to-face. However, some companies still invited motivational speakers for online speech session to motivate their employees.

HR managers have encountered challenges regarding safety regulations too, and worried that their staff might become ill with the virus. HRM has been concerned about interpreting and clarifying the regulations concerning the coronavirus issues. As stated by the experts, administrative workload has been reduced to HR professionals during the remote working period, however they had additional work to do in order to figure out and interpret the new regulations for their businesses, for their workplaces. 
Table 2 summarizes the main findings regarding the challenges an organisation, HR management, and employees have encountered as mentioned by the respondents.

Table 2: Challenges caused by the pandemic crisis

\begin{tabular}{|c|c|c|}
\hline Challenging areas to organisations & Challenges to Employees & Challenges to HRM \\
\hline $\begin{array}{l}\text { - Corporate Brand/ Image } \\
\text { - Organisational Culture/ Organisational } \\
\text { values } \\
\text { - Uncertainty/ Crisis Management } \\
\text { - Business closure / Suspended operations } \\
\text { - Regulations/ Imposed Fines } \\
\text { - Financial difficulties } \\
\text { - Flexibility } \\
\text { - Digitalisation }\end{array}$ & $\begin{array}{l}\text { - Stress } \\
\text { - Unemployment } \\
\text { - Unpaid leave } \\
\text { - Adaptability to remote } \\
\text { working } \\
\text { - Lack of Knowledge in } \\
\text { Online tools }\end{array}$ & $\begin{array}{l}\text { - Managing panic } \\
\text { - Avoiding dismissals } \\
\text { - Retaining employees } \\
\text { - Remote / online } \\
\text { Management } \\
\text { - Lack of Knowledge in } \\
\text { Technologies } \\
\text { - Lack of crisis Management } \\
\text { skills and knowledge } \\
\text { - New safety regulations }\end{array}$ \\
\hline
\end{tabular}

\subsection{The Future Roles of HRM}

The respondents ascertained that at first glance the crisis made it visible that HR professionals need more knowledge; despite many years of experience in this field, many of them lack skills and education especially in crisis management.

The experts state that although people are generally adaptable, the workforce still needs more skills, multidisciplinary education, as competition will be increased in the future.Jobs will be significantly transformed. Consequently, "employees are thinking about the development of competencies necessary to work in a digital environment, including digital sales, digital channel development, digital services, etc.” (R7, my translation).

There is a huge competition in the market, companies need highly developed people with the relevant knowledge, but more importantly with special skills who can adapt quickly to the environment, who can master new competences, are receptive to innovations, have the ability to learn, and possess creative innovative skills. Moreover, the workforce should take care of self-development.Companies must elaborate business continuity plan, and develop their human resources, opening up of internal resources and capabilities, build flexible processes, adopt new technologies, and create scenarios for business process continuity.

The experts recommended that top-management and HRM by the joint effort should design strategies to deal with the crisis focusing on flexibility and adaptability. To develop 'what if' scenarios can be beneficial for a company as well in preparing for future uncertainties. Furthermore, organisational culture plays a central role during the pandemic. Therefore, it is necessary for HRM to have frequent communication and close connection with employees. The company can overcome difficulties brought by the crisis easier when HR leadership encourages the workers, engages them, keeps them up-to-date, and takes into account their opinions.

The interviewees state that although the crisis occurred so sudden that companies could not change anything in their HRM approaches formally, yet the strategy is expected to be revised relating to crisis management, business continuity, and HRM processes.

However, remote working does not seem anymore as unthinkable for many companies, and HR professionals are now convinced that conducting trainings and meetings, or recruiting and hiring online are actually possible. Besides, close control of the employees is not so necessary as management thought before: "the person can work independently" (R2, my translation).

It is worth noting that emphasis of HRM should be put on emotional intelligence in order to make appropriate decisions from the viewpoint of management who tries to deal with a sudden crisis, and simultaneously from the perspective of the employees who have their own needs or difficulties caused by the pandemic. 


\section{Conclusion}

For this research, qualitative expert interview was used as a first orientation to better structure the problem resulting from the current crisis. The experts' opinions were based on their knowledge and personal experience. Data was interpreted, and comparisons were made to find main themes, similarities, and differences in the expert answers.

The research aimed to explore how Covid-19 pandemic affected activities of HR managers, and how organisations responded to the crisis from the viewpoint of HRM.

There are almost the same tendencies observed by the interviewed experts in Georgia as they are around the globe in this pandemic crisis according to the literature review. The researchers have theorized the similar trends experienced during the crisis situation regarding human resource management and impact on employee behaviour.

The current processes occurring in the companies as a response to the pandemic are complex, leading to many negative but also some positive outcomes. Employees and organisations are adapting to the new reality in order to achieve results. In this regard, emphasis should be placed on the internal communication to adapt quickly. Consequently, team spirit, friendship, collaboration, and cooperation are essential to survive in this changing environment. HR management makes a significant contribution by introducing online HR processes, training employees not only in skills required for performing current jobs, but also for developing those skills necessary for the future in case the circumstances change. HRM should focus on these issues in the personnel development programs.

On the one hand, companies should develop their human resources, as employees need to improve skills, and gain knowledge in order to better cope with uncertainties. On the other hand, however, crisis management dictates the companies to cut costs on training sessions and on other development activities. Thus, it is important that the HR management finds the right balance between cutting costs due to recession and developing the staff. Otherwise, effectiveness and efficiency cannot be achieved.

Future Research: Based on the research results of expert interviews, the questionnaire will be designed for the future quantitative survey of HR managers to study exhaustively the impact of Covid-19 crisis on the companies and on the HRM in Georgia. It would be interesting to obtain data about the organisational decisions, how employees and teams were working, how digitalisation and remote working affected companies, what were the main focus of HRM during the pandemic, and how HRM strategy has modified.

\section{References}

- Akkermans, J., Richardson, J., \& Kraimer, M. (2020). The Covid-19 crisis as a career shock: Implications for careers and vocational behavior. Journal of Vocational Behavior(119. Crossref

- Baker, S. E., \& Edwards, R. (2012). How many qualitative interviews is enough. Discussion Paper. NCRM. National Centre for Research Methods Review Paper.

- Bogner, A., Littig, B., \& Menz, W. (2009). Interviewing Experts. (A. Bogner, B. Litting, \& W. Menz, Eds.) Palgrave Macmillan. Crossref

- Bogner, A., Littig, B., \& Menz, W. (2009). Introduction: Expert interviews - An introduction to a new methodological debate. In A. Bogner, B. Littig, \& W. Menz (Eds.), Interviewing experts (pp. 1-13). London, UK: Palgrave Macmillan. Crossref

- Carnevale, J. B., \& Hatak, I. (2020). Employee Adjustment and Well-Being in the Era of COVID-19: Implications for Human Resource Management. Journal of Business Research(116), 183-187.. Crossref

- Cooper, D. R., \& Schindler, P. S. (2014). Business Research Methods (12 ed.). New-York: McGraw-Hill Irwin

- Corbin, J., \& Strauss, A. (2008). Basics of Qualitative Research: Techniques and Procedures for Developing Grounded Theory (3 ed.). Sage Publications, Inc. Crossref

- Donovan, A. (2019, January 28). What PwC Learned from Its Policy of Flexible Work for Everyone. Retrieved July 26, 2020, from Harvard Business Review: https://hbr.org/2019/01/what-pwc-learned-from-its-policy-of-flexiblework-for-everyone

- Flick, U. (Ed.). (2014). The Sage Handbook of Qualitative Data Analysis. Sage. Crossref 
- GCCI. (2020). COVID-19 Survey - Business Needs Assessment. Georgian Chamber of Commerce and Industry (GCCI.GE). Tbilisi: Georgian Chamber of Commerce and Industry.

- Giurge, L. M., \& Bohns, V. K. (2020, April 3). Harvard Business Review. Retrieved July 30, 2020, from 3 Tips to Avoid WFH Burnout: https://hbr.org/2020/04/3-tips-to-avoid-wfh-burnout

- Glaser, B. G., \& Strauss, A. L. (1967). The discovery of grounded theory: Strategies for qualitative research. Chicago: Aldine. Crossref

- Guest, G., Bunce, A., \& Johnson, L. (2006). How Many Interviews Are Enough?: An Experiment with Data Saturation and Variability. Field Methods, 181(1), 59-82. Crossref

- ILO. (2020). International Labour Organisation . Retrieved July 30, 2020, from COVID-19 Causes Devastating Losses In Working Hours And Employment: https://www.ilo.org/global/about-theilo/newsroom/news/WCMS_740893/lang--en/index.htm

- Kirby, S. (2020, June 2). 5 ways COVID-19 has changed workforce management. Retrieved July 2020, from World Economic Forum: https://www.weforum.org/agenda/2020/06/covid-homeworking-symptom-of-changing-face-ofworkforce-management/?fbclid=IwAR1wUy7_wQ6cKr_5ZN

- Libakova, N. M., \& Sertakova, E. A. (2015). The Method of Expert Interview as an Effective Research Procedure of Studying the Indigenous Peoples of the North. Journal of Siberian Federal University. Humanities \& Social Sciences, 1(8), 114-129.

- Mergel, I., Edelmann, N., \& Haug, N. (2019). Defining digital transformation: Results from expert interviews. Government Information Quarterly, 36(4), 101385.. Crossref

- Meuser , M., \& Nagel, U. (2002). Expertlnneninterviews- vielfach erprobt, wenig bedacht: Ein Beitrag zur qualitativen Methodendiskussion. In A. Bogner , B. Littig , \& W. Menz (Eds.), Das Expertinterview: Theorie, Methode, Anwendung (pp. 71-95). Wiesbaden: Springer Fachmedien.

- Narayandas, D., Hebbar, V., \& Liangliang, L. (2020, June 5). Lessons from Chinese Companies’ Response to Covid19. Retrieved July 28, 2020, from Harvard Business Review: https://hbr.org/2020/06/lessons-from-chinesecompanies-response-to-covid-19

- Parry, E., \& Battista, V. (2019). The impact of emerging technologies on work: a review of the evidence and implications for the human resource function [version 1; peer review: 2 approved, 1 approved with reservations]. Emerald Open Research, 1(5), Crossref

- Peasley, M. C., Hochstein, B., Britton, B. P., Srivastava, R. V., \& Stewart, G. T. (2020). Can't leave it at home? The effects of personal stress on burnout and T salesperson performance . Journal of Business Research (117), 58-70. Crossref

- PwC Georgia. (2020). Georgian Business in the face of the Covid-19 Pandemic . Tbilisi: PwC in Cooperation with Investors Council.

- Sheppard, B. (2020, May 18). A guide to thriving in the post-COVID-19 workplace. Retrieved July 30, 2020, from World Economic Forum: https:/www.weforum.org/agenda/2020/05/workers-thrive-covid-19-skills/

- Silverman, D. (2000). Doing qualitative research: A practical handbook. Thousand Oaks, CS: Sage.

- Singer-Velush, N., Sherman, K., \& Anderson, E. (2020, July 15). Microsoft Analyzed Data On Its Newly Remote Workforce . Retrieved July 30, 2020, from Harvard Business Review: https://hbr.org/2020/07/microsoft-analyzeddata-on-its-newly-remote-workforce

- Van der Lippe, T., \& Lippényi, Z. (2019). Co-workers working from home and individual and team performance. New Technology, Work and Employment, 35(1), 60-79. Crossref

- World Economic Forum. (2018). The Future of Jobs Report 2018 . Cologny/Geneva: Centre for the New Economy and Society. 